\title{
Radiation-induced lymphopenia correlates with survival in nasopharyngeal carcinoma: impact of treatment modality and the baseline lymphocyte count
}

Xiaoxue Xie ${ }^{1,2^{*}}$ D, Shenglan Gong ${ }^{1}$, Hekun Jin ${ }^{1,2}$, Pei Yang ${ }^{1,2}$, Ting X u $^{3}$, Yilong Cai ${ }^{1}$, Chengxian Guo ${ }^{4}$, Rong Zhang ${ }^{1,2}$, Fan Lou ${ }^{1,2}$, Wenjuan Yang ${ }^{1,2}$ and Hui Wang ${ }^{1,2}$

\begin{abstract}
Background and purpose: We evaluated the relationship between patient-, tumor-, and treatment-related features and radiation-induced lymphopenia (RIL) and evaluated the correlation between RIL and survival outcome in NPC patients to help improve the treatment strategy.

Methods: This retrospective study included 374 patients with stage II-IVa NPC who had been treated with definitive RT and were enrolled from 2004 to 2015; The associations between the G3-4 RIL (absolute lymphocyte count, $\mathrm{ALC}<0.5 \times 10^{9}$ cells $/ \mathrm{L}$ ) during RT and patient-, tumor-, and treatment-related factors were assessed using Cox regression analyses. The correlation between ALC nadir and survival was examined using a Kaplan-Meier analysis, compared with the log-rank test, and confirmed by a Cox proportional hazards analysis.

Results: In the multivariate analysis, lower baseline ALC and intensity modulated radiation therapy (IMRT) (vs. 2 dimensional-conformal radiation therapy,2D-CRT) were identified as 2 independent factors that were associated with G3-4 RIL. In the multivariate survival analysis, patients with G3-4 ALC nadir had longer local recurrence-free survival durations (LRFS) (vs. G0-2 nadir, $H R=0.548, P=0.005$ ) and longer progression-free survival durations (PFS) (vs. G0-2 nadir, $\mathrm{HR}=0.676, P=0.022$ ), while patients with $\mathrm{G} 4 \mathrm{ALC}$ nadir had a shorter distant-metastasis-free survival duration (DMFS) (vs. GO-2 nadir, hazard ratio $[H R]=2.567, P=0.037$ ).

Conclusions: In the study, lymphopenia during RT were affected by baseline ALC and RT modality independently. Moreover, G3-4 ALC nadir was independently linked with longer PFS and LRFS durations, while G4 ALC nadir was independently linked with a shorter DMFS duration.
\end{abstract}

\section{Introduction}

Nasopharyngeal carcinoma (NPC), which is the most common malignancy arising from the nasopharynx epithelium, is especially prevalent in southern China. Although the use of concurrent chemotherapy and intensity-modulated radiation therapy (IMRT) has provided a survival benefit [1-3], $20-30 \%$ of patients still

\footnotetext{
* Correspondence: tongwandou58@126.com

'Department of Radiation Oncology, Hunan Cancer Hospital, Affiliated Hospital of Xiangya Medical School, Central South University, Changsha 410013, Hunan, China

${ }^{2}$ Key Laboratory of Translational Radiation Oncology (2015TP1009), Changsha, China

Full list of author information is available at the end of the article
}

experience tumor relapse [4]. Identifying efficient prognostic factors could help us stratify patients who are at high risk of tumor relapse.

Radiation therapy (RT) is the primary treatment for NPC. It might also directly suppress immune function via the direct destruction of mature circulating lymphocytes, a cell type that exhibits significant DNA fragmentation, even at low radiation doses (<1 Gy) [5-7]. Tang et al. [8] found that among patients undergoing chemotherapy, higher lung V5 to V10 exhibited the greatest association with lower lymphocyte nadir $(P<0.001)$. In addition to the lungs, irradiated dose and volume of the bone marrow and spleen are also strongly associated

(c) The Author(s). 2020 Open Access This article is distributed under the terms of the Creative Commons Attribution 4.0 International License (http://creativecommons.org/licenses/by/4.0/), which permits unrestricted use, distribution, and 
with lymphocyte destruction $[9,10]$. Therefore, it is possible that larger RT fields expose more circulating cells to radiation and thus result in lymphocyte destruction, otherwise known as radiation-induced lymphopenia (RIL).

Studies have found that absolute lymphocyte count (ALC) is a marker of immune health [11] and is correlated with patient outcomes, particularly overall survival (OS), progression-free survival (PFS), and distant metastasis-free survival (DMFS) in numerous cancers, including NPC $[12,13]$. We have observed decreases in the lymphocyte population during the RT period in NPC patients. However, there is only a limited number of publications about the relationship between RIL and survival in NPC patients. Therefore, we evaluated the relationship between patient-, tumor-, and treatment-related features and RIL and evaluated the correlation between RIL and survival outcome in NPC patients.

\section{Materials and methods}

\section{Patients}

A total of 374 previously untreated NPC patients was enrolled between October1 2004 and May31 2015 from radiation oncology department of Hunan cancer hospital. The eligibility criteria were as follows:(1) biopsyproven World Health Organization 1, 2, or 3, histopathologic type NPC; (2) Stage II-IVa disease according to the eighth edition of the international Union against Cancer/American Joint Committee on Cancer staging system; (3) no evidence of distant metastases before primary treatment; (4) Eastern cooperative Oncology Group performance status grade 0 or 1; and (5) A definitive radiation therapy for NPC was completed without delay.

Exclusion criteria included the following: (1) Patients without disease progression and followed less than 1 year; and (2) co-existence of a secondary malignancy, pregnancy, or lactation.

\section{Treatment}

Of these patients, $69.8 \%$ were treated with $2 \mathrm{D}$-CRT and $30.2 \%$ were treated with IMRT. $87.2 \%$ of the patients received cisplatin-based chemotherapy before or during RT; 35\% of the patients received adjuvant chemotherapy. All IMRT plans and 2D-CRT plans were delivered by a $6 \mathrm{MV}$ linear accelerator (Varian Medical Systems, Palo Alto, CA). Radiation was administered five times per week. All patients were treated according to the treatment principles for NPC patients at our institute.

\section{IMRT}

The gross tumor volumes of both the primary tumor (GTVnx) and the radiologically involved cervical nodes (GTVnd) were outlined on the planning CT images with the aid of MRI images. The corresponding pGTVnx (70
Gy-74 Gy) and pGTVnd (66 Gy-68 Gy) with a $5 \mathrm{~mm}$ margin encompassing GTVnx and GTVnd. The clinical target volumes CTV1 (60Gy-66Gy) and CTV2 (50Gy56Gy) respectively encompassing the high and low risk areas. The corresponding PTV1 and PTV2 with a $5 \mathrm{~mm}$ margin encompassing CTV1 and CTV2 were created by Boolean operations of the treatment planning system. OARs included brainstem, spinal cord, globes, optic nerves, optic chiasm, lenses, temporomandibular joints, temporal lobes auditory nerves, cochleae, mandible, oral cavity, larynx, parotid glands and vestibules. During IMRT optimization, the maximum dose of brainstem, optic nerves and chiasm must be $\leq 54 \mathrm{~Gy}$ (allowing $0.1 \mathrm{cc}$ brainstem $<60$ Gy)and spinal cord $\leq 45 \mathrm{~Gy}$. Efforts were also made to limit mean dose of parotid glands to $26 \mathrm{~Gy}$ whenever possible and dose to the lenses and temporal lobes as low as reasonably achieved without compromising dose coverage to the PTVs.

\section{D-CRT}

Two opposing lateral portals are used to cover primary nasopharyngeal cancer in nasopharyngeal cavity and adjacent normal tissue with high risk of tumor subclinical infiltration. A single front portal was used to cover the lower cervical lymph node area. 8-12 MeV electron irradiation was used to boost dose on metastatic cervical lymph nodes. Prescription dose was 70Gy-76Gy for primary tumor and 66Gy-70Gy for cervical nodes. High and low risk areas received 60Gy-66Gy and 50Gy-56Gy respectively. Brainstem must be protected by lead blocks completely when irradiation dose reach 50Gy and spinal cord must be protected by lead blocks completely when irradiation dose reach 40Gy.

\section{Lymphocyte count}

The complete blood count was determined using a Sysmex XN-9000 automated hematology analyzer (Sysmex, Kobe, Japan). The ALC was assessed prior to RT and weekly thereafter until the completion of RT. Additional complete blood count tests were performed in patients who developed a specific condition during treatment. The ALC baseline was assessed less than 7 days before treatment (RT or induction chemotherapy), and the minimum ALC during RT was identified as the ALC nadir.

RIL of different extents was defined as grade (G) 4 $\left(\mathrm{ALC}<0.2 \times 10^{9}\right.$ cells $\left./ \mathrm{L}\right), 3\left(\mathrm{ALC} \geq 0.2 \times 10^{9}\right.$ cells $/ \mathrm{L}$ and $<$ $0.5 \times 10^{9}$ cells $\left./ \mathrm{L}\right), 2\left(\mathrm{ALC} \geq 0.5 \times 10^{9}\right.$ cells $/ \mathrm{L}$ and $<0.8 \times$ $10^{9}$ cells $\left./ \mathrm{L}\right), \quad 1 \quad\left(\mathrm{ALC} \geq 0.8 \times 10^{9}\right.$ cells $/ \mathrm{L}$ and $<1.0 \times 10^{9}$ cells/L), or 0 (ALC $\geq 1.0 \times 10^{9}$ cells/L) during the RT periods ( 1 to 8 weeks), consistent with the lymphopenia grade (which was determined according to Common Terminology Criteria for Adverse Events [CTCAE] version 4.0). To analyze the cumulative incidence of highlevel RIL (G3 and G4), we recorded the first time the 
ALC declined below $0.2 \times 10^{9}$ cells $/ \mathrm{L}$ and $0.5 \times 10^{9}$ cells/ L for each patient.

\section{Outcome and follow-up}

The outcomes were progression-free survival (PFS), distant metastasis-free survival (DMFS), local recurrence-free survival (LRFS), and overall survival (OS) duration. The follow-up time and time to event were measured from the date of the first day of RT until the event (including recurrence and metastasis) or until the patient was censored. Patients' medical histories were obtained, and physical examinations and nasopharyngoscopies were performed at each follow-up visit. Nasopharynx and neck MRI, chest Xray, and abdominal sonography were routinely performed on an annual basis or upon a clinical indication of tumor relapse.

\section{Statistical analysis}

A Cox regression model was used in the univariate and multivariate analyses to assess the effect of patient-, tumor-, and treatment-related factors on G3-4 RIL. These factors included age, sex, baseline ALC, body mass index, smoking index (pack ${ }^{*}$ years), clinical disease stage, histology, chemotherapy condition, and RT modality (2D-CRT or IMRT). The criteria for including (or excluding) factors in the forward-conditional multivariate Cox regression model for high-level RIL were $P<0.1$ for inclusion and $P>0.05$ for removal. KaplanMeier 1 minus survival curves were generated for the cumulative incidence of high-level RIL by risk factors.

In the survival analysis, for each endpoint (PFS, DMFS, LRFS, and OS), outcomes by RIL based on ALC nadir values during $\mathrm{RT}$ were compared using the log-rank test and Cox regression analysis. Co-factors in the multivariate analysis included age, sex, baseline ALC, body mass index, smoking index (pack*years), clinical disease stage, histologic type, chemotherapy condition, and RT modality. The criteria for including (or excluding) factors in the forwardconditional multivariate Cox regression model for cumulative incidence of tumor relapse (recurrence or metastasis) were $P<0.1$ for inclusion and $P>0.05$ for removal.

All variables were analyzed as continuous if possible. All statistical tests were 2-sided, and analyses were performed using the SPSS ver.24.0 statistical software package (IBM Corp., Armonk, NY).

\section{Results}

\section{Baseline patient characteristics}

Table 1 lists the characteristics of the 374 patients (262 men and 112 women with a median age of 46 years; range, 17-70 years). The median (inter quartile range) follow-up time was 52.2 months (5.0-119.8 months). According to CTCAE 4.0, 33 (8.8\%) patients had an ALC
Table 1 Baseline demographic, tumor, and treatment characteristics of 374 NPC patients

\begin{tabular}{|c|c|}
\hline Characteristic & Result \\
\hline \multicolumn{2}{|l|}{ Sex, N (\%) } \\
\hline Female & $112(29.9)$ \\
\hline Male & $262(70.1)$ \\
\hline Age at diagnosis, years (median, range) & $46(17-70)$ \\
\hline $\begin{array}{l}\text { ALC baseline before treatment } \times 10^{9} \text { cells } / L \\
\text { (median, range) }\end{array}$ & $1.81(0.25-3.5)$ \\
\hline Body mass index, $\mathrm{kg} / \mathrm{m}^{2}$ (median, range) & $22.60(15.60-33.77)$ \\
\hline Smoking status, pack*year (median,range) & $0(0-120)$ \\
\hline \multicolumn{2}{|l|}{ Tumor histologic type (WHO), N (\%) } \\
\hline Non-keratinized undifferentiated (III) & $145(38.8)$ \\
\hline Non-keratinized differentiated (II) & $220(58.8)$ \\
\hline Keratinized (I) & $9(2.41)$ \\
\hline \multicolumn{2}{|l|}{ T status, N (\%) } \\
\hline $\mathrm{T} 1$ & $37(9.9)$ \\
\hline $\mathrm{T} 2$ & $133(35.6)$ \\
\hline T3 & $156(41.7)$ \\
\hline $\mathrm{T} 4$ & $48(12.8)$ \\
\hline \multicolumn{2}{|l|}{ N status, N (\%) } \\
\hline NO & $31(82.9)$ \\
\hline N1 & $80(21.4)$ \\
\hline N2 & $227(60.7)$ \\
\hline N3 & $36(9.6)$ \\
\hline \multicolumn{2}{|l|}{ Stage $^{a}, N(\%)$} \\
\hline$\|$ & $46(12.3)$ \\
\hline III & $245(65.5)$ \\
\hline IVa & $83(22.2)$ \\
\hline Prescribed dose of GTVnx,Gy, (median, range) & $72.7(68-82)$ \\
\hline \multicolumn{2}{|l|}{ Induction or concurrent chemotherapy, N (\%) } \\
\hline None & $48(12.8)$ \\
\hline Induction only & $62(16.6)$ \\
\hline Concurrent only & $70(18.7)$ \\
\hline Both & $194(51.9)$ \\
\hline \multicolumn{2}{|l|}{ Adjuvant chemotherapy, N (\%) } \\
\hline Yes & $131(35.0)$ \\
\hline No & $243(65.0)$ \\
\hline \multicolumn{2}{|l|}{ Radiation modality, N (\%) } \\
\hline 2D-CRT & $261(69.8)$ \\
\hline IMRT & $113(30.2)$ \\
\hline
\end{tabular}

Abbreviations: $C l$ confidence interval, $H R$ hazard ratio, 2D-CRT 2-dimensional conventional radiotherapy, IMRT intensity modulated radiation therapy, GTV gross tumor volume, WHO World Health Organization, ALC absolute lymphocyte count

${ }^{a}$ American Joint Committee on Cancer, eighth edition 


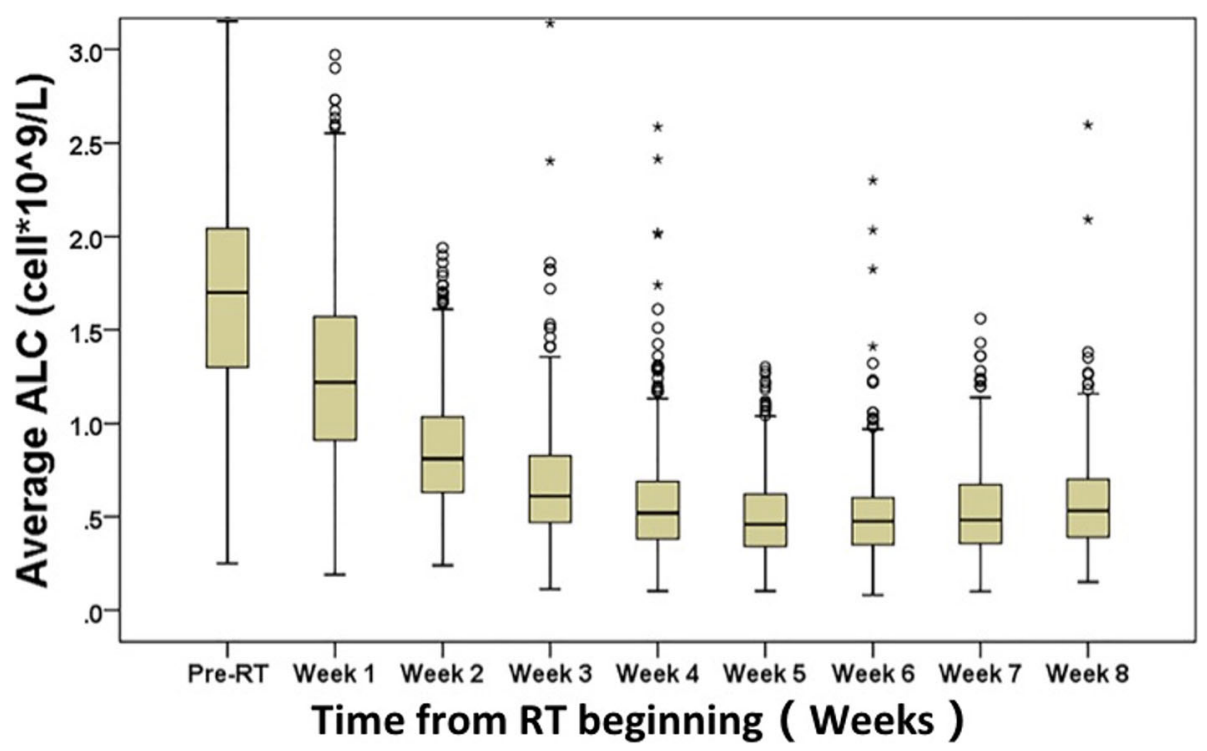

Fig. 1 Absolute lymphocyte count (ALC) trend from before radiation therapy (pre-RT) through week 8 during RT

Table 2 Univariate Cox regression analysis demonstrates associations between baseline variables and lymphocyte nadirs during RT

\begin{tabular}{|c|c|c|c|c|c|c|}
\hline \multirow[t]{2}{*}{ Characteristic } & \multicolumn{3}{|c|}{ ALC $<0.5 \times 10^{9}$ Cells $/ L$} & \multicolumn{3}{|c|}{ ALC $<0.2 \times 10^{9}$ Cells $/ L$} \\
\hline & $\mathrm{HR}$ & $95 \% \mathrm{Cl}$ & $P$ value & $\mathrm{HR}$ & $95 \% \mathrm{Cl}$ & $P$ value \\
\hline \multicolumn{7}{|l|}{ Sex } \\
\hline Female & 1 & & & 1 & & \\
\hline Male & 0.997 & $0.772-1.288$ & 0.636 & 1.424 & $0.672-3.018$ & 0.357 \\
\hline Age at diagnosis (years) & 0.992 & $0.979-1.004$ & 0.183 & 0.964 & $0.932-0.997$ & 0.033 \\
\hline ALC baseline & 0.591 & $0.469-0.744$ & $<0.001$ & 0.443 & $0.235-0.834$ & 0.012 \\
\hline Body mass index & 0.961 & $0.925-0.998$ & 0.041 & 0.935 & $0.836-1.045$ & 0.236 \\
\hline Smoking status (pack*year) & 1 & $0.999-1.000$ & 0.193 & 1 & $0.999-1.001$ & 0.636 \\
\hline \multicolumn{7}{|l|}{ Tumor histologic type (WHO) } \\
\hline Undifferentiated (III) & 1 & & & 1 & & \\
\hline Differentiated (I and II) & 0.666 & $0.516-1.525$ & 0.887 & 1.152 & $0.535-2.481$ & 0.717 \\
\hline \multicolumn{7}{|l|}{ Stage } \\
\hline$\|$ & 1 & & & 1 & & \\
\hline III & 1.419 & $0.941-2.139$ & 0.102 & 1.942 & $0.455-8.284$ & 0.37 \\
\hline Iva & 1.53 & $0.968-2.416$ & 0.097 & 4.098 & $0.931-18.037$ & 0.062 \\
\hline \multicolumn{7}{|c|}{ Induction or concurrent chemotherapy (N) } \\
\hline None & 1 & & & 1 & & \\
\hline Induction only & 1.201 & $0.757-1.9007$ & 0.971 & 0.794 & $0.230-2.745$ & 0.716 \\
\hline Concurrent only & 1.142 & $0.726-1.796$ & 0.566 & 1.221 & $0.409-3.644$ & 0.721 \\
\hline Both & 1.545 & $1.043-2.290$ & 0.03 & 1.011 & $0.375-2.725$ & 0.983 \\
\hline \multicolumn{7}{|l|}{ RT modality } \\
\hline 2D-CRT & 1 & & & 1 & & \\
\hline IMRT & 1.594 & $1.233-2.061$ & $<0.001$ & 2.148 & $1.099-4.200$ & 0.025 \\
\hline
\end{tabular}




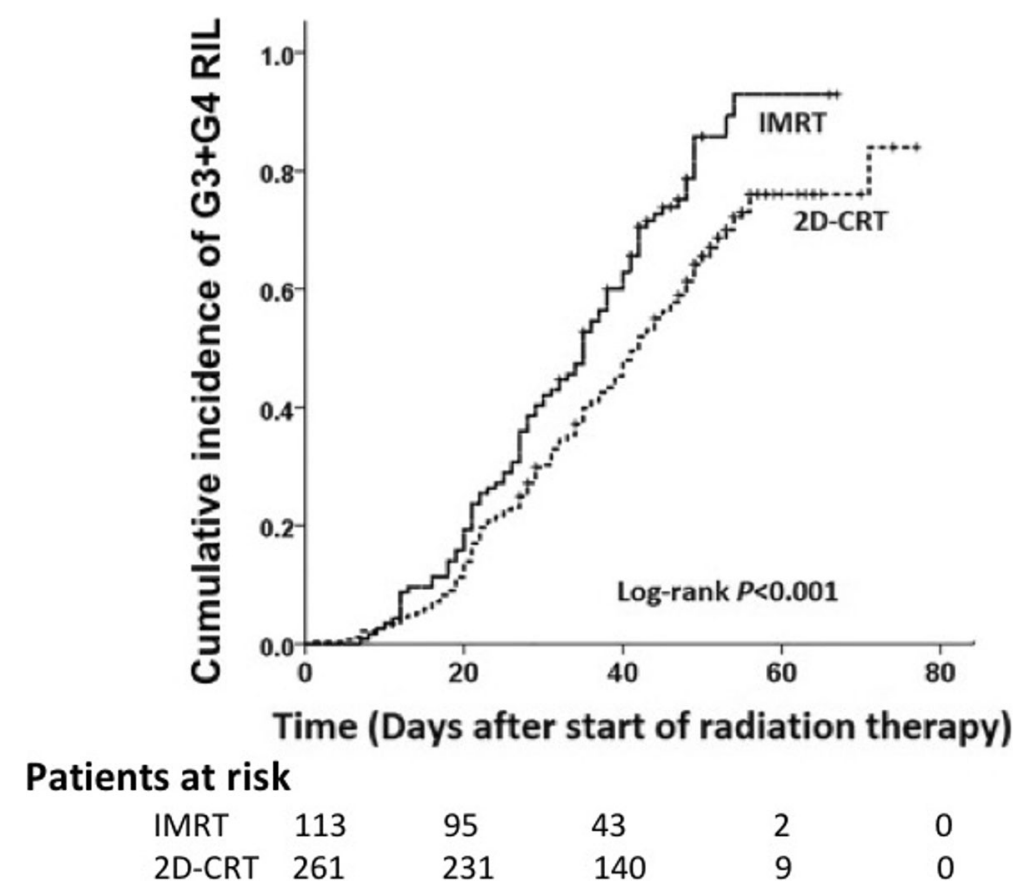

Fig. 2 Kaplan-Meier curves show the comparison of the cumulative incidence of grade 3-4 (G3-4) radiation-induced lymphopenia (RIL) (absolute lymphocyte count $[\mathrm{ALC}]<0.5 \times 10^{9} / \mathrm{L}$ ) after intensity-modulated radiation therapy (IMRT) and 2D-conventional radiation therapy (2D-CRT)

baseline $<1 \times 10^{9}$ cells $/ \mathrm{L}$, and $341(91.2 \%)$ had an ALC baseline $>1 \times 10^{9}$ cells $/ \mathrm{L}$.

\section{Lymphocyte counts during RT}

To visualize the peripheral blood lymphocyte trends during RT, we plotted ALCs with respect to time during RT in weeks (Fig. 1). There were 12(3.2\%) patients with G0/1 nadir, 57 (15.2\%) with G2 nadir, 274 (73.3\%) with G3 nadir, and 31 (8.3\%) with G4 nadir.

\section{Association between patient characteristics and incidence of high-level RIL}

In the univariate analysis, we found that baseline ALC (HR $=0.591, P<0.001)$ and RT modality (IMRT vs. $2 \mathrm{D}$ CRT, $\mathrm{HR}=1.594, P<0.001)$ were significantly associated with the G3-4 RIL (Table 2). Cumulative incidence curves illustrate the effects of RT modality (IMRT vs. 2D-CRT) on ALC during RT (Fig. 2).
In the multivariate analysis, we confirmed that a lower baseline ALC and that IMRT (vs. 2D-CRT) were two independent negative factors for the G3-4 RIL (Table 3).

\section{Lymphocyte nadir is associated with patient outcomes}

Of the 374 patients who were available for survival analysis, 158(42.25\%) experienced events within the followup period, including $85(22.72 \%)$ with local regional failure, 65(17.38\%) with distant metastatic failure, and $8(2.14 \%)$ with local regional and metastatic failure at the same time. The survival curves shown in Fig. 3 illustrate the correlations between ALC nadir and LRFS and DMFS. Log-rank tests and univariate analysis showed significant relationships between ALC nadirs and LRFS. Patients with G3-4 nadirs showed longer LRFS duration when compared to G0-2 nadir (Fig. 3a, c and Table 4); No significant difference was found between G3-4 nadir and G0-2 nadir for DMFS durations (Fig. 3d and Table 4). However, patients with G4 nadir during RT were at a

Table 3 Multivariate Cox regression analysis demonstrates two clinical characters as independent risk factors for lymphopenia during RT

\begin{tabular}{|c|c|c|c|c|c|c|}
\hline \multirow[t]{2}{*}{ Characteristic } & \multicolumn{3}{|c|}{ ALC $<0.5 \times 10^{9}$ Cells $/ L$} & \multicolumn{3}{|c|}{ ALC $<0.2 \times 10^{9}$ Cells $/ L$} \\
\hline & $\mathrm{HR}$ & $95 \% \mathrm{Cl}$ & $P$ value & $\mathrm{HR}$ & $95 \% \mathrm{Cl}$ & $P$ value \\
\hline ALC baseline & 0.563 & $0.440-0.719$ & $<0.001$ & 0.423 & $0.224-0.800$ & 0.008 \\
\hline RT modality (IMRT vs. 2D-CRT) & 1.651 & $1.251-2.179$ & $<0.001$ & 2.042 & $1.011-4.124$ & 0.046 \\
\hline
\end{tabular}



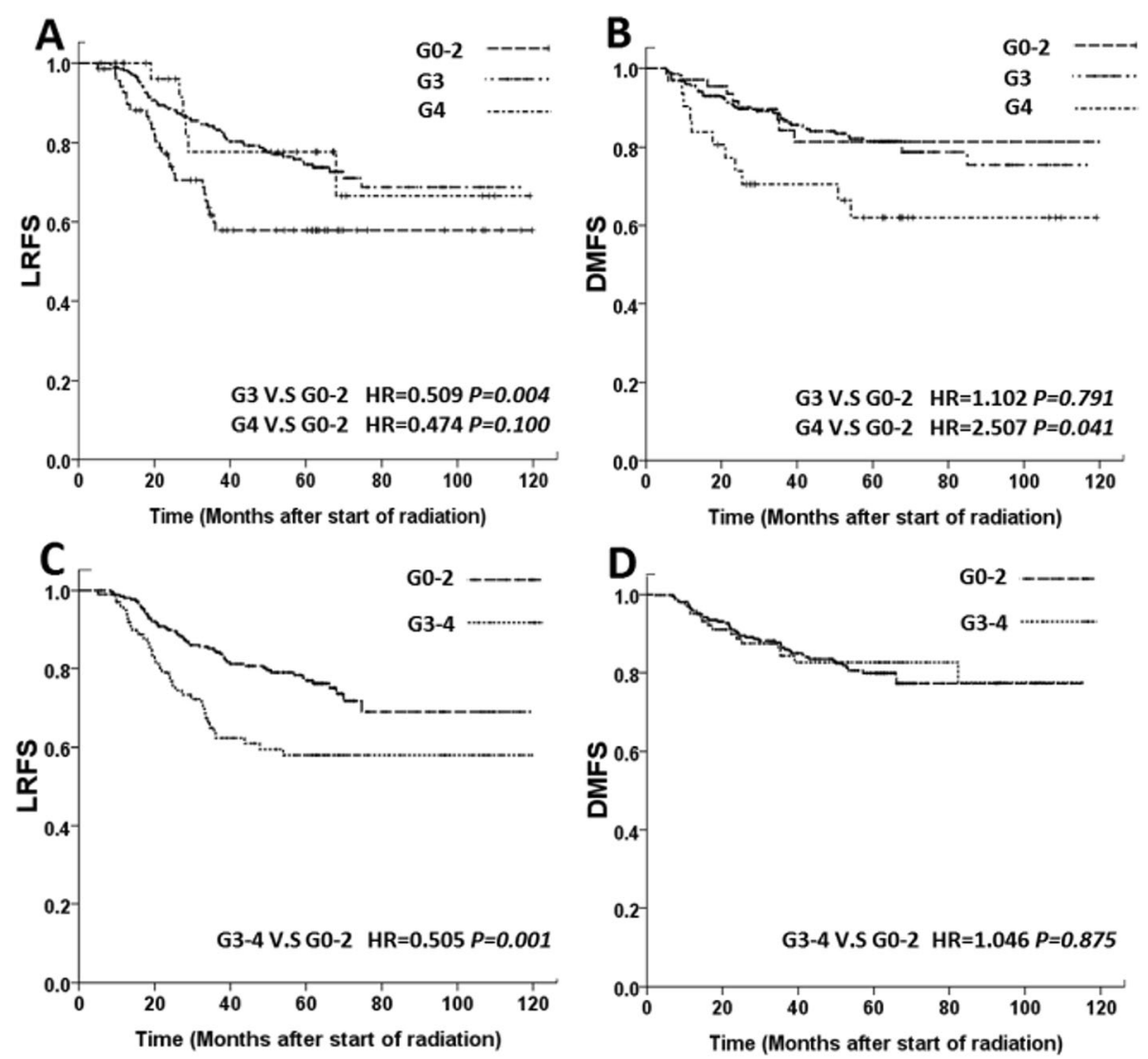

Fig. 3 Kaplan-Meier curves show distant metastasis-free survival (DMFS) (a and c), local recurrence-free survival (LRFS) (b and d) of nasopharyngeal patients, grouped by lymphopenia grade (Common Terminology Criteria for Adverse Events 4.0) based on ALC nadir during RT

higher risk of distant metastasis while comparing to G02 nadir during RT (Fig. 3b and Table 4).

In the multivariate analysis, G3-4 nadir showed longer LRFS duration (vs. G0-2 nadir, HR $=0.548, P=0.005$ ), and longer PFS duration (vs. G0-2 nadir, $\mathrm{HR}=0.676, P=0.022$ ); No significant difference was found between patients with G3-4 nadir and G0-2 nadir for DMFS. While patients with G4 nadir during RT showed shorter DMFS (vs. G0-2 nadir, $\mathrm{HR}=2.567, P=0.037$ ) during RT (Table 5).

\section{Discussion}

RIL is affected by radiation therapy modality and baseline lymphocyte count

In this study, we evaluated the correlation between patient-, tumor-, and treatment-related features and RIL in NPC patients. We found that both baseline ALC and RT modality were independently associated with RIL.

Although only $33(8.82 \%)$ patients were diagnosed with lymphopenia (ALC baseline $<1 \times 10^{9}$ cells/L) before treatment, relatively lower level of lymphocyte baseline was associated with both incidence of G3 and G4 RIL, regardless of induction chemotherapy or concurrent chemotherapy use. Thus, the high-level lymphopenia during RT may have already been present (i.e., intrinsic immunosuppression that was enhanced by RT).

In this study, we showed that IMRT led to a greater decrease in ALC than did 2D-CRT. The analysis of RT techniques (IMRT vs. 2D-CRT) indicated that the incidence of high-level RIL during RT was significantly higher after IMRT than after 2D-CRT. Nevertheless, 2DCRT is unlikely to be a better choice than IMRT after a comprehensive evaluation. Instead, the regular usage of low-dose volume restriction of surrounding normal tissue should be considered when planning IMRT. It is known that IMRT can greatly improve the uniformity and conformity of dose distribution on target volume compared with traditional $2 \mathrm{D}-\mathrm{CRT}$ by compromising a larger volume of low-dose irradiation upon surrounding normal tissue [14]. Lymphocytes are known to be the most radiosensitive of the peripheral blood cells, with an $\mathrm{LD}_{50}$ as low as $2 \mathrm{~Gy}$ [15], and the incidental doses received when lymphocytes are within the radiation portal during fractionated RT could be sufficient to result in lymphopenia [16]. In reality, any low-dose-irradiated 
Table 4 Univariate Cox regression analysis demonstrates associations between ALC nadirs and baseline variables and outcomes during RT

\begin{tabular}{|c|c|c|c|c|c|c|c|c|c|}
\hline \multirow[t]{2}{*}{ Characteristic } & \multicolumn{3}{|l|}{ PFS } & \multicolumn{3}{|l|}{ DMFS } & \multicolumn{3}{|l|}{ LRFS } \\
\hline & $\mathrm{HR}$ & $95 \% \mathrm{Cl}$ & $P$ value & $\mathrm{HR}$ & $95 \% \mathrm{Cl}$ & $P$ value & $\mathrm{HR}$ & $95 \% \mathrm{Cl}$ & $P$ value \\
\hline \multicolumn{10}{|l|}{ RIL grade (nadir) } \\
\hline G3 V.S G0-2 & 0.662 & $0.451-0.970$ & 0.034 & 1.102 & $0.538-2.255$ & 0.791 & 0.509 & $0.322-0.807$ & 0.004 \\
\hline G4 V.S G0-2 & 0.998 & $0.559-1.781$ & 0.993 & 2.507 & $1.038-6.053$ & 0.041 & 0.474 & $0.195-1.153$ & 0.1 \\
\hline G3-4 V.S G0-2 & 0.668 & $0.480-0.930$ & 0.017 & 1.046 & $0.594-1.842$ & 0.875 & 0.505 & $0.333-0.766$ & 0.001 \\
\hline \multicolumn{10}{|l|}{ Sex } \\
\hline Female & 1 & & & 1 & & & 1 & & \\
\hline Male & 1.6 & $1.103-2.321$ & 0.013 & 2.129 & $1.167-3.882$ & 0.014 & 1.245 & $0.792-1.958$ & 0.342 \\
\hline Age at diagnosis (years) & 0.996 & $0.980-1.013$ & 0.649 & 1.003 & $0.980-1.028$ & 0.78 & 0.991 & $0.970-1.012$ & 0.388 \\
\hline Lymphocyte baseline & 0.992 & $0.740-1.331$ & 0.958 & 0.928 & $0.585-1.472$ & 0.751 & 1.039 & $0.710-1.521$ & 0.844 \\
\hline Body mass index & 0.975 & $0.927-1.025$ & 0.319 & 0.992 & $0.920-1.065$ & 0.779 & 0.956 & $0.893-1.023$ & 0.193 \\
\hline Smoking status (pack*year) & 1 & $1.000-1.001$ & 0.039 & 1 & $1.000-1.001$ & 0.128 & 1 & $1.000-1.001$ & 0.192 \\
\hline \multicolumn{10}{|l|}{ Tumor histology (WHO) } \\
\hline Undifferentiated (III) & 1 & & & 1 & & & 1 & & \\
\hline Differentiated $(I+I I)$ & 1.402 & $1.003-1.960$ & 0.048 & 1.445 & $0.880-2.371$ & 0.146 & 1.285 & $0.836-1.973$ & 0.253 \\
\hline \multicolumn{10}{|l|}{ Stage } \\
\hline$\|$ & 1 & & & 1 & & & 1 & & \\
\hline III & 1.335 & $0.786-2.266$ & 0.285 & 1.811 & $0.715-4.587$ & 0.21 & 1.257 & $0.662-2.385$ & 0.485 \\
\hline IVa & 1.78 & $1.001-3.163$ & 0.049 & 3.41 & $1.307-8.897$ & 0.012 & 1.095 & $0.517-2.321$ & 0.813 \\
\hline Prescribed dose (Gy) & 0.994 & $0.955-1.033$ & 0.749 & 1 & $0.942-1.061$ & 0.991 & 0.986 & $0.939-1.036$ & 0.575 \\
\hline \multicolumn{10}{|c|}{ Induction or concurrent chemotherapy } \\
\hline None & 1 & & & 1 & & & & & \\
\hline Induction only & 0.545 & $0.333-0.890$ & 0.015 & 0.8 & $0.367-1.743$ & 0.574 & 0.472 & $0.257-0.867$ & 0.016 \\
\hline Concurrent only & 0.463 & $0.272-0.790$ & 0.005 & 0.85 & $0.385-1.876$ & 0.688 & 0.286 & $0.136-0.601$ & 0.001 \\
\hline Both & 0.477 & $0.315-0.724$ & $<0.001$ & 0.673 & $0.338-1.339$ & 0.259 & 0.388 & $0.232-0.649$ & $<0.001$ \\
\hline \multicolumn{10}{|l|}{ Adjuvant chemotherapy } \\
\hline No & 1 & & & 1 & & & 1 & & \\
\hline Yes & 0.959 & $0.687-1.338$ & 0.806 & 1.341 & $0.837-2.150$ & 0.223 & 0.69 & $0.435-1.094$ & 0.115 \\
\hline \multicolumn{10}{|l|}{ Radiation modality } \\
\hline 2D-CRT & 1 & & & 1 & & & 1 & & \\
\hline IMRT & 0.857 & $0.606-1.210$ & 0.38 & 0.998 & $0.609-1.636$ & 0.994 & 0.783 & $0.495-1.238$ & 0.295 \\
\hline
\end{tabular}

Abbreviations: Cl confidence interval, HR hazard ratio, 2D-CRT 2-dimensional conventional radiotherapy, IMRT intensity modulated radiation therapy, WHO World Health Organization

tissue surrounding the target volume can be considered the organ at risk for lymphopenia because peripheral lymphocytes circulate throughout the body and exist in all tissues. Thus, a large volume of even very low-dose irradiation (i.e., a greater "low-dose bath") may result in more lymphocyte destruction. In order to compare the dose distribution between 2D-CRT and IMRT plans, we created 2D-CRT plans on 6 patients who had received IMRT. It showed that compared with IMRT the absolute total volume of receiving at least 5Gy (body V5) in 2D-CRT was greatly reduced (Supplementary fig. 1 and supplementary table 1). For the limitations of 2D-CRT, it is no longer commonly used for NPC patients. Therefore, the most important recommendation from our results should be restriction on low-dose irradiation(e.g. Body V5)in IMRT plans.

\section{ALC nadir during RT correlates with survival}

In the survival analysis, Patients with G3-4 nadir during $\mathrm{RT}$ were at a lower risk of local reginal recurrence than patients with $\mathrm{G} 0-2$ lymphopenia $(\mathrm{HR}=2.567, P=0.037$ ).

A large number of retrospective and prospective studies have shown that low lymphocyte nadir is associated 
Table 5 Multivariate Cox regression analysis demonstrates associations between ALC nadirs and baseline variables and outcomes during RT

\begin{tabular}{|c|c|c|c|c|c|c|c|c|c|}
\hline \multirow[t]{2}{*}{ Characteristic } & \multicolumn{3}{|l|}{ PFS } & \multicolumn{3}{|c|}{ DMFS } & \multicolumn{3}{|l|}{ LRFS } \\
\hline & $\mathrm{HR}$ & $95 \% \mathrm{Cl}$ & $P$ value & $\mathrm{HR}$ & $95 \% \mathrm{Cl}$ & $P$ value & $\mathrm{HR}$ & $95 \% \mathrm{Cl}$ & $P$ value \\
\hline \multicolumn{10}{|l|}{ RIL grade (nadir) } \\
\hline G3 V.S G0-2 & 0.637 & $0.434-0.936$ & 0.022 & $\mathrm{NI}$ & - & - & 0.491 & $0.310-0.780$ & 0.003 \\
\hline G4 V.S G0-2 & $\mathrm{NI}$ & - & - & 2.567 & $1.059-6.219$ & 0.037 & $\mathrm{NI}$ & - & - \\
\hline G3-4V.S G0-2 & 0.676 & $0.484-0.945$ & 0.022 & $\mathrm{NI}$ & - & - & 0.548 & $0.360-0.835$ & 0.005 \\
\hline \multicolumn{10}{|l|}{ Sex } \\
\hline Female & 1 & & & 1 & & & $\mathrm{NI}$ & & \\
\hline Male & 1.556 & $1.070-2.263$ & 0.021 & 2.005 & $1.097-4.080$ & 0.025 & $\mathrm{NI}$ & - & - \\
\hline \multicolumn{10}{|l|}{ Stage } \\
\hline$\|$ & 1 & & & $\mathrm{NI}$ & & & $\mathrm{NI}$ & & \\
\hline III & 1.632 & $0.940-20,832$ & 0.082 & $\mathrm{NI}$ & - & - & $\mathrm{NI}$ & - & - \\
\hline IVa & 2.04 & $1.115-3.731$ & 0.007 & $\mathrm{NI}$ & - & - & $\mathrm{NI}$ & - & - \\
\hline \multicolumn{10}{|c|}{ Induction or concurrent chemotherapy } \\
\hline None & 1 & & & & & & 1 & & \\
\hline Induction only & 0.422 & $0.254-0.701$ & 0.001 & $\mathrm{NI}$ & - & - & 0.386 & $0.210-0.709$ & 0.002 \\
\hline Concurrent only & 0.299 & $0.172-0.520$ & $<0.001$ & $\mathrm{NI}$ & - & - & 0.206 & $0.098-0.434$ & $<0.001$ \\
\hline Both & 0.294 & $0.191-0.453$ & $<0.001$ & $\mathrm{NI}$ & - & - & 0.265 & $0.159-0.443$ & $<0.001$ \\
\hline
\end{tabular}

Abbreviations: $H R$ hazard ratio, $C l$ confidence interval, $S D$ standard deviation, $G T V$ gross tumor volume, $A L C$ absolute lymphocyte count

with poor patient outcomes [17-23]. Cho et al. [12] reported that NPC patients with a minimum ALC $<245$ cells $/ \mu \mathrm{L}$ had worse PFS durations. Liu et al. [13] found that lymphopenia (mini-ALC $<390$ cells $/ \mu \mathrm{L}$ and post3mALC $<705$ cells $/ \mu \mathrm{L}$ ) was strongly correlated with shorter DMFS and PFS durations in patients with NPC. Since a large number of publications have reported the correlation between lymphopenia and poor prognosis, we were surprised that G3-4 lymphopenia was beneficial predictor of LRFS and PFS in the present study.

Generally, RT can cause severe lymphopenia, leading to the suppression of host anti-cancer immunity; however, it can also stimulate tumor antigen release, which activates the $\mathrm{T}$ lymphocytes and enhances the host's anti-cancer immunity. In fact, the presence of tumorinfiltrating lymphocytes, which are mainly composed of cytotoxic $\mathrm{T}$ lymphocytes, has been associated with better patient outcomes in melanoma and head and neck cancers $[24,25]$. On the basis of our results, we assumed that, besides direct damage to lymphocytes by RT, lymphocytes infiltrating from the peripheral blood after stimulation with RT may lead to a reduction in circulating lymphocytes, which presents as lymphopenia. On the other hand, the radiosensitivity of lymphocytes may also be representative of the radiosensitivity of cancer cells [26], which predicts better survival.

However, among the 4 grades of lymphopenia, G4 nadir was associated with the shortest DMFS duration, which might be attributable to more immuno-suppression than immuno-stimulation induced by RT. Based on the result, it seems reasonable why no advance was found for PFS and OS in patients with G3-4, which showed advance for LRFS though. Therefore, G3 but not G4 nadir during RT may be indicative of an individually appropriate radiation dose that is able to stimulate anti-cancer immunity and defeat cancer cells without significantly influencing the host's anti-cancer immunity.

Our study is subject to several limitations. In the survival analysis, we did not observe a significant correlation either between OS and RIL, or between OS and any patient-, tumor-, or treatment-related features (e.g., sex, age, clinical disease stage, radiation modality, and chemotherapy condition). We studied patients over 12 years; the substantial changes in social environments and common lifestyles could have contributed to the negative result in the OS analysis. In addition, our data were exclusively obtained from 1 center; the findings from the current study should be validated in a larger, multicenter study.

In conclusion, baseline ALC and RT modality, which were independently associated with RIL, should be considered carefully when developing a personalized RT plan. Moreover, G3-4 nadir was linked with longer LRFS durations, while G4 nadir was linked with a shorter DMFS duration; thus, routinely follow-up is more important for patients with G4 nadir as well as those with G0-2 nadir. 


\section{Supplementary information}

Supplementary information accompanies this paper at https://doi.org/10. 1186/s13014-020-01494-7.

Additional file 1: Table S1. Comparison of V5 $\left(\mathrm{mm}^{3}\right)$ between IMRT and 2D-CRT plans in 6 patients

Additional file 2: Figure S1. Dosimetric comparison between 2D-CRT $(A, B, C)$ and IMRT $(D, E, F)$. Note: The yellow line indicates the 5Gy isodose contour

\section{Acknowledgements}

We thank the patients who volunteered to participate in this trial. We thank Ann Sutton and her department of Scientific Publications in MD Anderson Cancer Center and for their editorial guidance in the development and finalization of the article.

\section{Authors' contributions}

$X X X, C X G$, and HKJ designed the study. XXX, HKJ, YLC, and SLG analyzed and interpreted the patient data regarding the lymphopenia and clinic outcome. $X X X$ and PY performed the statistical analysis. SLG, XXX, and TX wrote the manuscript. SLG, RZ, FL, WYJ, and HW conducted the follow-up. All authors read and approved the final manuscript.

\section{Funding}

Funding supported by the Natural Science Foundation of China No.81301942, Hunan Natural Science Foundation No. 2017JJ3191, and Hunan Provincial Health and Wellness Committee Foundation No. 2015109. They all had the roles in the design of the study and collection, analysis, and interpretation of data and in writing the manuscript.

\section{Availability of data and materials}

The datasets analyzed during the current study are available from the corresponding author on reasonable request.

\section{Ethics approval and consent to participate}

The study was approved by our institution.

\section{Consent for publication}

The consent for publication was obtained from every patient.

\section{Competing interests}

The authors declare that they have no competing interests.

\section{Author details}

'Department of Radiation Oncology, Hunan Cancer Hospital, Affiliated Hospital of Xiangya Medical School, Central South University, Changsha 410013, Hunan, China. ${ }^{2}$ Key Laboratory of Translational Radiation Oncology (2015TP1009), Changsha, China. ${ }^{3}$ Radiation Oncology, The University of Texas MD Anderson Cancer Center, Houston, TX, USA. ${ }^{4}$ Center of Clinical Pharmacology, The Third Xiangya Hospital, Central South University, Changsha, China.

Received: 28 October 2019 Accepted: 14 February 2020

Published online: 14 March 2020

\section{References}

1. Al-Sarraf M, LeBlanc M, Giri PG, Fu KK, Cooper J, Vuong T, et al. Chemoradiotherapy versus radiotherapy in patients with advanced nasopharyngeal cancer: phase III randomized intergroup study 0099. J Clin Oncol. 1998;16(4):1310-7.

2. Chan AT, Teo PM, Ngan RK, Leung TW, Lau WH, Zee B, et al. Concurrent chemotherapy-radiotherapy compared with radiotherapy alone in locoregionally advanced nasopharyngeal carcinoma: progression-free survival analysis of a phase III randomized trial. J Clin Oncol. 2002;20(8): 2038-44.

3. Lee AW, Tung SY, Ngan RK, Chappell R, Chua DT, Lu TX, et al. Factors contributing to the efficacy of concurrent-adjuvant chemotherapy for locoregionally advanced nasopharyngeal carcinoma: combined analyses of NPC-9901 and NPC-9902 trials. Eur J Cancer. 2011:47(5): 656-66.

4. Sun X, Su S, Chen C, Han F, Zhao C, Xiao W, et al. Long-term outcomes of intensity-modulated radiotherapy for 868 patients with nasopharyngeal carcinoma: an analysis of survival and treatment toxicities. Radiother Oncol. 2014;110(3):398-403.

5. Verastegui EL, Morales RB, Barrera-Franco JL, Poitevin AC, Hadden J. Longterm immune dysfunction after radiotherapy to the head and neck area. Int Immunopharmacol. 2003;3(8):1093-104.

6. Sellins KS, Cohen JJ. Gene induction by gamma-irradiation leads to DNA fragmentation in lymphocytes. J Immunol. 1987;139:3199-206.

7. Stratton JA, Byfield PE, Byfield JE, Small RC, Benfield J, Pilch Y. A comparison of the acute effects of radiation therapy, including or excluding the thymus, on the lymphocyte subpopulations of cancer patients. J Clin Invest. 1975;56: 88-97.

8. Tang C, Liao Z, Gomez D, Levy L, Zhuang Y, Gebremichael RA, et al. Lymphopenia association with gross tumor volume and lung $V 5$ and its effects on non-small cell lung cancer patient outcomes. Int J Radiat Oncol Biol Phys. 2014;89:1084-91.

9. Chadha AS, Liu G, Chen HC, Das P, Minsky BD, Mahmood U, et al. Does unintentional splenic radiation predict outcomes after pancreatic cancer radiation therapy? Int J Radiat Oncol Biol Phys. 2017:97(2):323-32.

10. Cho O, Chun M, Chang SJ, Oh YT, Noh OK. Prognostic value of severe lymphopenia during pelvic concurrent chemo radiotherapy in cervical cancer. Anticancer Res. 2016;36(7):3541-7.

11. Sansoni $P$, Cossarizza A, Brianti $V$, Fagnoni F, Snelli G, Monti D, et al. Lymphocyte subsets and natural killer cell activity in healthy old people and centenarians. Blood. 1993;82(9):2767-73.

12. Cho O, Oh YT, Chun M, Noh OK, Hoe JS, Kim H. Minimum absolute lymphocyte count during radiotherapy as a new prognostic factor for nasopharyngeal cancer. Head Neck. 2016;38:E1061-7.

13. Liu LT, Chen QY, Tang LQ, Guo SS, Guo L, Mo HY, et al. The prognostic value of treatment-related lymphopenia in nasopharyngeal carcinoma patients. Cancer Res Treat. 2018;50(1):19-29.

14. Bucci MK, Bevan A, Roach M 3rd. Advances in radiation therapy: conventional to 3D, to IMRT, to 4D, and beyond. CA Cancer J Clin. 2005 55(2):117-34 Review.

15. Nakamura N, Kusunoki Y, Akiyama M. Radiosensitivity of CD4 or CD8 positive human T-lymphocytes by an in vitro colony formation assay. Radiat Res. 1990;123(2):224-7.

16. Venkatesulu BP, Mallick S, Lin SH, Krishnan S. A systematic review of the influence of radiation-induced lymphopenia on survival outcomes in solid tumors. Crit Rev Oncol Hematol. 2018;123:42-51.

17. Davuluri R, Jiang W, Fang P, Xu C, Komaki R, Gomez DR, et al. Lymphocyte nadir and esophageal cancer survival outcomes after chemoradiation therapy. Int J Radiat Oncol Biol Phys. 2017:99(1):128-35.

18. Campian JL, Ye X, Brock M, Grossman SA. Treatment-related lymphopenia in patients with stage III non-small-cell lung cancer. Cancer Investig. 2013;31: 183-8.

19. Campian JL, Sarai G, Ye X, Marur S, Grossman SA. Association between severe treatment-related lymphopenia and progression-free survival in patients with newly diagnosed squamous cell head and neck cancer. Head Neck. 2014;36(12):1747-53.

20. Wild AT, Ye X, Ellsworth SG, Smith JA, Narang AK, Garg T, et al. The association between chemoradiation-related lymphopenia and clinical outcomes in patients with locally advanced pancreatic adenocarcinoma. Am J Clin Oncol. 2015:38:259-65.

21. Mehrazin R, Uzzo RG, Kutikov A, Ruth K, Tomaszewski JJ, Dulaimi E, et al. Lymphopenia is an independent predictor of inferior outcome in papillary renal cell carcinoma. Urol Oncol. 2015;33(9):388.e19-25.

22. Grossman SA, Ellsworth S, Campian J, Wild AT, Herman JM, Laheru D, et al. Survival in patients with severe lymphopenia following treatment with radiation and chemotherapy for newly diagnosed solid tumors. J Natl ComprCancNetw. 2015;13(10):1225-31.

23. Cho O, Oh YT, Chun M, Noh OK, Lee HW. Radiation-related lymphopenia as a new prognostic factor in limited-stage small cell lung cancer. Tumour Biol. 2016:37:971-8

24. Uryvaev A, Passhak M, Hershkovits D, Sabo E, Bar-Sela G. The role of tumorinfiltrating lymphocytes (TILS) as a predictive biomarker of response to antiPD1 therapy in patients with metastatic non-small cell lung cancer or metastatic melanoma. Med Oncol. 2018;35(3):25 
25. Lei Y, Xie Y, Tan YS, Prince ME, Moyer JS, Nör J, Wolf GT. Telltale tumor infiltrating lymphocytes (TIL) in oral, head \& neck cancer. Oral Oncol. 2016; 61:159-65.

26. Słonina D, Gasińska A. Intrinsic radiosensitivity of healthy donors and cancer patients as determined by the lymphocyte micronucleus assay. Int I Radiat Biol. 1997;72(6):693-701.

\section{Publisher's Note}

Springer Nature remains neutral with regard to jurisdictional claims in published maps and institutional affiliations.

Ready to submit your research? Choose BMC and benefit from:

- fast, convenient online submission

- thorough peer review by experienced researchers in your field

- rapid publication on acceptance

- support for research data, including large and complex data types

- gold Open Access which fosters wider collaboration and increased citations

- maximum visibility for your research: over $100 \mathrm{M}$ website views per year

At $B M C$, research is always in progress.

Learn more biomedcentral.com/submissions 